\title{
DESIGN STUDENTS VIEWPOINT ON BIM: A PRELIMINARY ASSESSMENT OF THE INDICATORS
}

\author{
D. F. Çapkın ${ }^{1}$, Ü. Işıkdağ ${ }^{* 2}$, T. Tong ${ }^{1}$ \\ ${ }^{1}$ YTU, Dept.of.Architecture, Architecture Faculty, 34349 Yıldız Istanbul, Turkey - dursun.furkan.capkin@ std.yildiz.edu.tr, \\ tong@yildiz.edu.tr \\ ${ }^{* 2}$ Dept. of Informatics, Mimar Sinan Fine Arts University, 34380 Istanbul, Turkey - umit.isikdag@msgsu.edu.tr
}

\author{
Commission IV, WG IV/1
}

KEY WORDS: BIM, Perception, Viewpoint, Students, Survey

\begin{abstract}
:
Building Information Modelling (BIM) has been the most popular Architecture, Engineering and Construction (AEC) technology and information management approach for the last 5 years. The popularity of the approach not only comes from its role in enabling an efficient exchange of information and collaboration between the stakeholders of a construction project, but also is related with the benefits it has provided in detecting possible errors in the design phase, and providing means for the elimination of these errors as early as possible and thus minimizing the time and financial loss in the project. The training related to BIM is provided in the undergraduate and post-graduate levels, also with certification programs. The viewpoint of the students/trainees is closely related to their attitude towards BIM. The research explained in this paper aimed to identify the viewpoint of design school students on Building Information Modelling. The study started with a literature review on the foundational concepts regarding BIM. The second stage of the study included data collection with a questionnaire survey. Later this data is explored through descriptive statistics, and some foundational hypothesis on the impact of group differences on the BIM viewpoint were tested. The findings indicate that the viewpoint of design school students shows a positive tendency towards using and implementing BIM in real-life projects. Besides, the group differences (such as gender, level, department) do not appear to have an impact on the viewpoint.
\end{abstract}

\section{INTRODUCTION}

Building Information has gained more attention in the last 10 years due to the public sector's demand and paradigm shift in design practices towards more collaborative working. The key advantage offered by the BIM approach and related technologies was eliminating possible errors that can occur during the construction in earlier phases of the building lifecycle. This advantage has been adequately comprehended by the AEC industry in recent years. These factors have resulted in more investments in BIM related technologies, which has increased the demand towards BIM workforce and BIM training. An important aspect of any training is understanding the viewpoint and level of knowledge of trainees on the subject, before curriculum development. The vantage point of the trainer/training organisation can be determined more clearly based on the knowledge related to the trainee viewpoint and knowledge level. If a clear picture can be viewed from the trainer side, this would lead to more successful curriculum development. In this context, it is important to know the BIM viewpoint and BIM attitudes of trainees or possible trainees is important for any academic organisation. Recent literature contains various examples of research in this field including studies on sentiments, perceptions, awareness and acceptance levels. Key studies are further explained in the following section. Although these studies highlight different factors related to the viewpoint of students on BIM, further studies need to be conducted to understand the global picture. This research focused on contributing to this field by providing the viewpoint on BIM from the perspective of Turkish students. The paper starts with a background on the subject, this section is followed by the methods section where the details of the research methodology are explained. The paper continues with the results section where results and explained and finalized by presenting the research findings.

\section{BACKGROUND}

Building Information Modelling (BIM) is defined by international standards as the process of "getting benefit through better specification and delivery of just the right amount of information concerning the design, construction and management of buildings and infrastructure, using appropriate technology tools." (ISO 19650, 2018). The Building Information Model is stemmed from product models that are utilized in the aerospace, mechanical, building and electrical product design. The product modelling approach has emerged with the aim of facilitating the sharing and exchange of information through the use of a common shared model residing centrally. All stakeholders of the design and production process can reach, interact and update this model, and shares the ability to reach the most up-to-date version of the model. Thanks to the advancements in cloud computing today the ability to collaborate and cooperate regardless of time and space, does not only facilitate design process but also helps the production processes to become smoother and leaner while increasing the quality and thus the value of the final products. Having derived this approach from the production industries, the AEC industry has expanded the concept of product modelling into what can now be called a new way of working for the design and construction of buildings. The BIM approach provides means for representing buildings throughout the entire lifecycle as semantically enriched, consistent, digital building models (Sacks et al., 2018). BIM is supported with object-oriented computer-assisted design software. This type of software consists of parametric objects

\footnotetext{
*Corresponding Author
} 
representing building components (Lee et al., 2006). In BIM software the objects are the building blocks of the overall semantically rich digital model and have geometric or nongeometric attributes with functional, semantic or topologic information (Wong, Yang, 2010). According to Ghaffarianhoseinia et al., (2017). The utilization of BIM in the AEC industry has gained momentum after the emergence of the industry-standard information model, IFC, in the late 1990s, but the real industry uptake started after 2010 when public sector and governments have issued legal requirements and mandates forcing the industry to use this BIM-based tools, technologies and information management practices. In parallel with the industrial uptake the requirement for professionals with knowledge of BIM has increased, which in turn resulted in BIM courses and training programs in academia and industry. In recent years the BIM has become a natural element of the curriculum of architecture and design faculties. There exist various BIM courses and training programs in most parts of the world at undergraduate and postgraduate levels. It is important to understand the viewpoints, perceptions and levels of uptake for the students of BIM courses to define and develop better curricula in these programs. Several studies exist in the literature regarding this topic. In a recent effort, Suwal \& Singh (2018) explored student's sentiments regarding BIM, who are enrolled in a construction project management course. They found out that students prefer to work on practical implementations over theoretical work because they consider it more important for a future industry job. Another reason for that is practical assignments give more freedom for students to learn at their own pace. According to research by Sotelino et al., (2020) students were able to understand that BIM is more than just using a software tool like Revit. In this respect, the students pointed out that BIM helps them to understand the whole design-to-construction process better. Students also stated that they understood how BIM improves efficiency gains and it improved their ability to get engaged in multidisciplinary tasks. BIM tools allowed them to take into account a greater amount of information, and thanks to BIM, many more aspects of the project can be tested more quickly at the initial conceptual mass stage. In another study by Ahn \& Kim (2016), it is shown that the architecture students in Asia generally used CAD software and had rarely experienced BIM training and interacted with BIM software. The authors argued that student's understanding of BIM was affected by three factors: BIM awareness, IFC recognition and IFC interest. Students who are more aware of BIM are more interested in it. Students in upper levels/grades were more aware of BIM because they had completed more training and used tools compared to other students. According to Zou at al., (2019) students' perceptions of BIM usefulness and their BIM-related job interest depend on contemporary industry practice despite their lack of industry experience. AEC students' perceptions of BIM are more affected by real-world applications than scientific research. Male students have more positive opinions about BIM. Deniz (2018) demonstrated that students are aware of BIM related industry needs and their carrier opportunities about BIM. Many students believed that BIM tools are rising but some of them were not sharing the same idea. Opposing views may be due to students' experiences as they were using 2D drafting instruments instead of BIM tools at the time of the study. $79 \%$ of the students participated in that research believed in the value of BIM tools such as Revit. Besides, $86 \%$ believed that BIM tools would be beneficial for their future career. The perception of students on BIM speciality revealed their interest in learning BIM tools in the undergraduate level. In a recent study, Shelbourn (2017) indicated that the students' perception of BIM was not clear. This was due to lack of expertise and the students could not be able to create a relationship between their discipline and how to adopt BIM in their field. The examples part from the literature is a small part of the ongoing discussion on how students perceive BIM and what can be done to help them develop a positive attitude. The studies in the area indicate a research gap in the literature as they are providing local views. There need to be more studies conducted to understand the global picture on the issue, and every new study has a potential to identify and connect the pieces of the puzzle and help to see a bigger picture on the perception of BIM by the students.

\section{METHODS}

Research Aim and Focus: To help in bridging the explored research gap, this study aimed to identify the viewpoint of design school students on Building Information Modelling. The objectives of the research included understanding the views of the students and exploring if these views change within the subgroups based on gender, department, and level/grade.

Data Collection Instrument: The data collection instrument was selected as the questionnaire survey. The questions in the survey were prepared based on the findings of the literature review. The questions were prepared with the focus of understanding the views towards Building Information Modelling. The total number of questions in the survey was 13 The first three questions were related to the demographics, asking about the gender, the department the students are in and their grade/level. The remaining 10 questions were focused on understanding the viewpoint towards Building Information Modelling. The participants were asked to provide their level of agreement in the 5-point Likert Scale to the provided statements. The data is collected through a period of 2 months in 2019.

Target Population and Sampling: The target population was design school students at university (bachelor) level living in Turkey. Simple random sampling is used as the sampling strategy (Health Knowledge, 2020). The questionnaire is developed as an online instrument and sent to a target sample size of 350 students in faculties of Design and Architecture using Google $\odot$ Forms. The response rate was $75 \%$, this high rate was due to the effort of authors in tracking the situation of the questionnaires with their students. The number of responses/realised sample size was 258 , this sampling rate would enable the measurement of the target population and with 0.05 margin of error and with a confidence level of $85 \%$ (Research Advisors, 2020).

\section{RESULTS}

\subsection{Data Screening}

The data was downloaded from Google Forms following the completion of the survey as a spreadsheet and imported into a statistical software package for screening and analysis. All the data screening and analysis have been completed using SPSS, a very well-known statistical analysis package for social sciences. The steps of the data screening stage included the checks for missing and inconsistent data. One row was removed due to the inconsistent data. There was no missing data in the dataset.

\subsection{Exploratory Analysis of Socio-Demographics}

The next stage of the exploratory analysis included the visualisation of the frequencies of the demographic variables. 


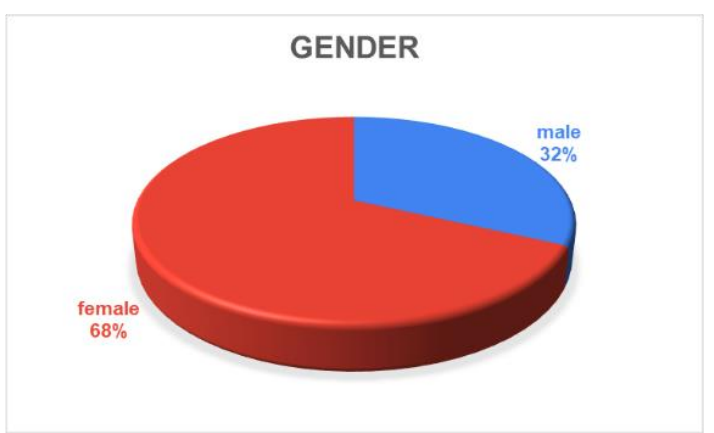

Figure 1. Gender Distribution

As shown in Fig. 1 the gender distribution of the participants is skewed towards females, which is in parallel with the gender distribution in design and architecture schools in Turkey.

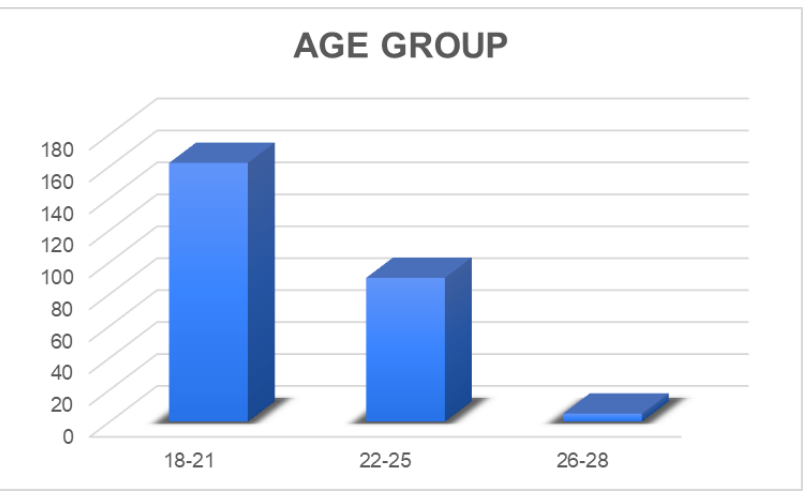

Figure 2. Age Group Distribution

Fig. 2 shows the distribution of the age-group of the survey participants. The most commonly found age group was $18-21$, this is followed by $22-25$ and a few participants were in $26-28$ age group. The skewness towards the 18-21 age group is natural as the age of university students range between 18-23 in Turkey in normal circumstances.

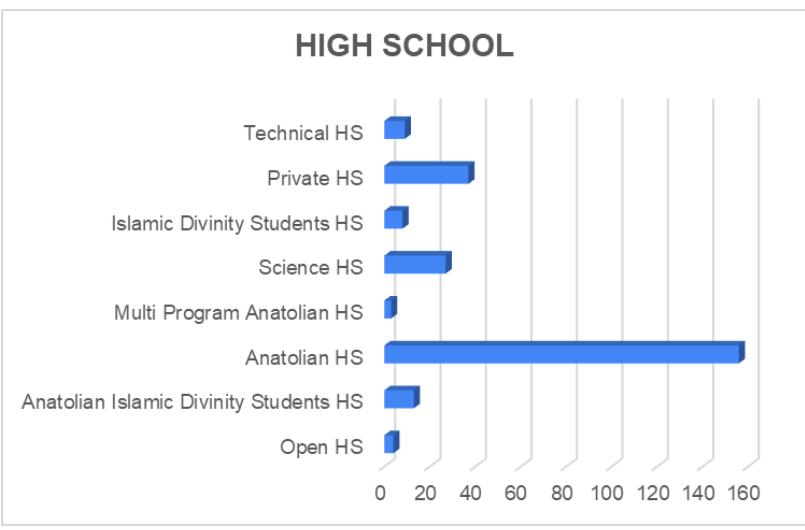

Figure 3. High School Graduation

As shown in Fig. 3 majority of the participants were graduates of Anatolian High Schools which are known to be providing a good level of English training. This is followed by Private High schools which are also known as providers of training and education in English. This is followed by Science High School which is known to be strong in mathematics, physics, chemistry, and biology. This followed by Islamic Divinity Students High Schools which provide training with the focus of Islamic Sciences, there were also a few participants who were graduates of Technical High Schools and Open High School.

As illustrated in Fig. 4., most of the respondents were studying in the department of Architecture, this is followed by the Department of Interior Architecture. A low number of participants were from the Departments of Landscape Design and Industrial Design. As the survey is related to BIM distribution of the survey participants among departments is normal, as the students of Architecture and Interior Architecture are more concerned about BIM when compared to other related design disciplines. mostly in one of the Architectural disciplines and either at their $2^{\text {nd }}$ or $4^{\text {th }}$ (final) year of university education.

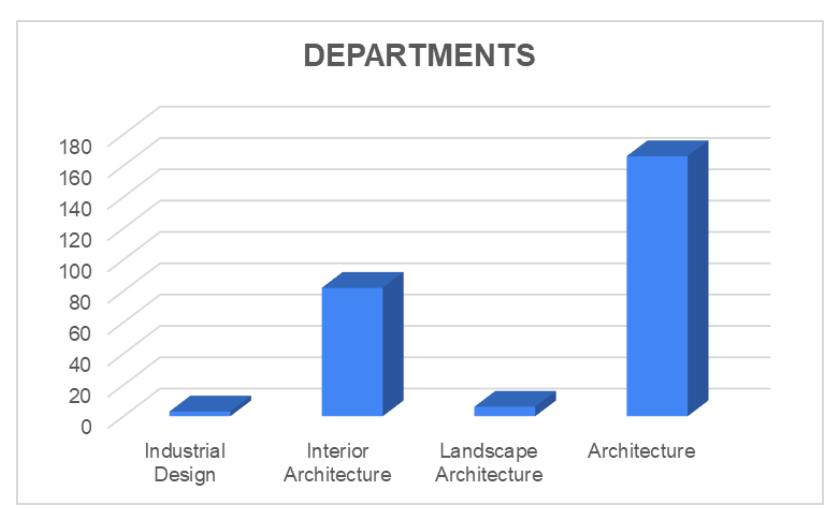

Figure 4. Department of Participants

The majority of the students were from the Somophore Level (i.e. year 2) and Senior Level (i.e. year 4 ) which provides an equal distribution of the first half and second half of their university life. The participants representing the Junior (year 3) level was limited. The demographics demonstrated that the participants are relatively young, majorly female, their majority has a good level of English knowledge. (Fig.5)

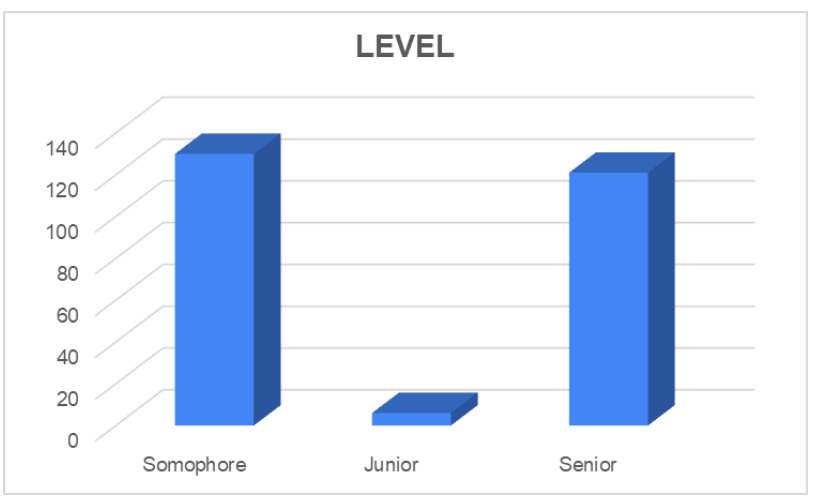

Figure 5. Level/Grade of Participants

\subsection{Descriptive Statistics}

This section provides descriptive statistics for 10 statements where the participant's level of agreement is measured with 5 point Likert Type items. The first statement(Q1) was an argument towards BIM facilitates the coordination in design. Majority of the participants either agreed or strongly agreed (Fig. 6). .It is apparent that the role of BIM in facilitating coordination in design is well understood. 

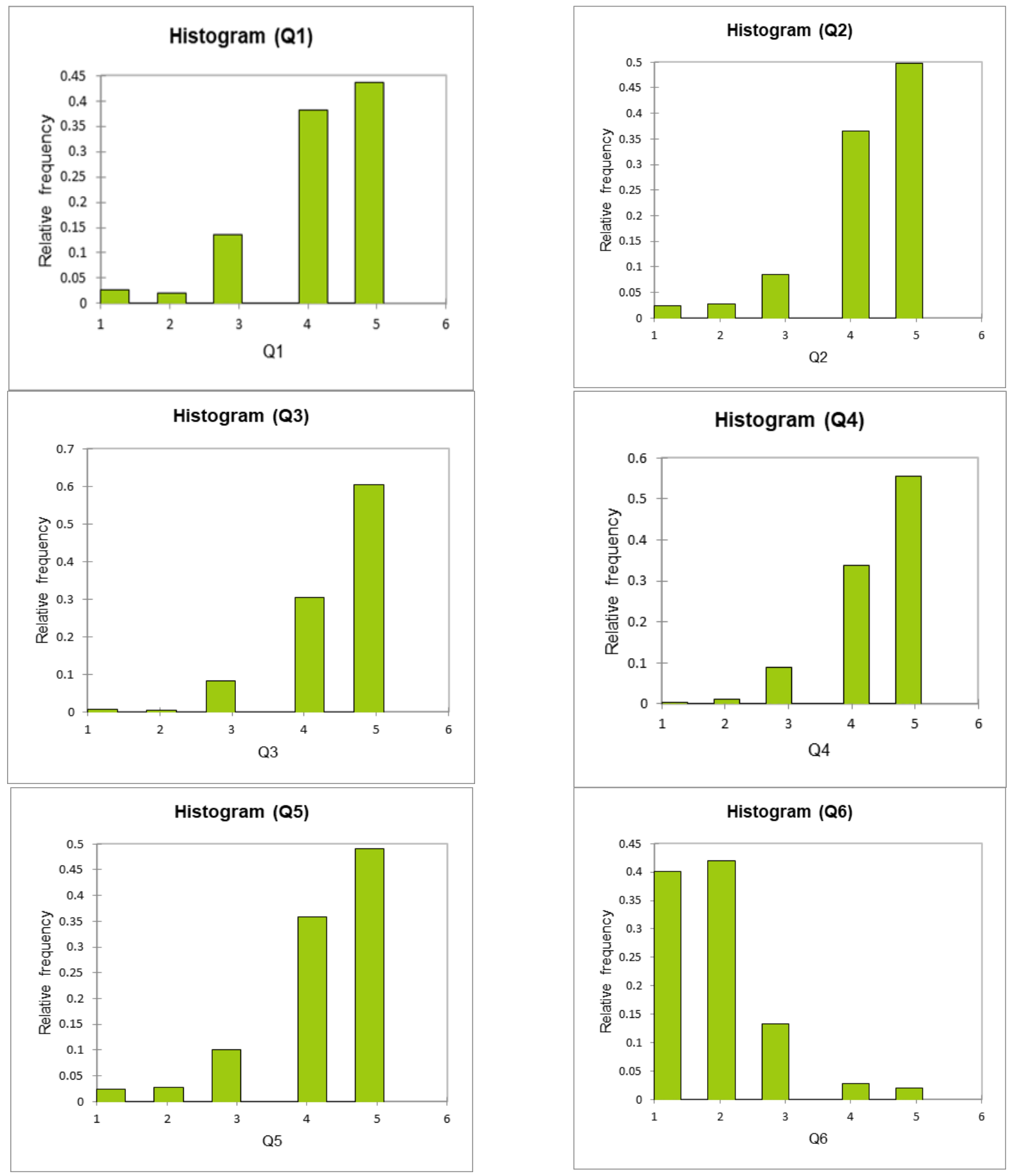

Figure 6. Histograms of Q1-Q6

The second statement (Q2) was expressing that BIM should be viewed as an important asset in AEC projects. Similar to the previous statement the majority participants, $85 \%$ (Fig. 6), supports this idea of viewing BIM as a key asset of a project.

This indicates that the students have a rapid uptake on the role of the BIM. Building Information Modelling has different dimensions related to its utilization in time, cost and facilities management. In that sense, as one of its dimension(4D), BIM plays an important role in facilitating the simulation of the construction activities. The third statement indicated that simulation of the processes in construction sites enables us to detect the possible errors in advance and would provide us with the chance to correct them before the start of the actual construction. The third statement advocates that BIM-based process simulations enable the early discovery of errors in the construction process. The agreement level with this statement is 90\%, and there is no disagreement at all (Fig. 6) which shows the role of BIM in preventing the errors in the construction phase is well understood. The fourth statement mentions that the utilization of BIM in the design and construction stages will reduce the error rate in projects. This is a more generalized 
statement expressing the role of BIM to decrease the error rate in projects either during the pre-design, design or in the construction stage. As shown in Fig. 6 a vast majority of the participants agree with this idea. This indicates that with using BIM the participants believe that they will work in a less error-prone environment. The use of BIM not only would have local impacts and will lead to specific gains, but it would as well have a role in the increased quality on the management of the project and the final product/structure. The fifth statement indicates that implementing BIM in the design phase would improve the quality and efficiency of the project. As illustrated in Fig.6 above $80 \%$ of the participants and agree with this statement while the disagreement rate is below $10 \%$.

The knowledge management in the project's lifecycle is related to many dimensions including the existence of well-defined processes, well-established information and knowledge management strategy, well-documented information flows, organized input and outputs. BIM as a model and BIM as an information management strategy contributes highly to the knowledge management practices, by formalizing the information exchanges and flows and also by controlling the type and nature of the information that would be shared or exchanged. The next statement of the survey argued that BIM (as a model or process) is unnecessary for successful knowledge management. The participants majorly disagreed with this argument (Fig.6), confirming the positive role of BIM in the knowledge management processes. The disagreement ration was above $80 \%$. One of the key focus areas of project management is finding the optimum combination of time, cost and quality and this is known as the TCQ optimisation. The optimization focuses on planning and constructing a building with optimum time-cost combination and with a quality level above a pre-determined threshold. To achieve this, data from the planning stage including the bill of quantities, time plan, cost of materials, customer requirements are input into an optimisation environment to find out the optimum solution. The simulations run for the optimisation process, when completed without visual inspection of the $3 \mathrm{D}$ model, would not provide accurate results although the results might look correct mathematically. A visual inspection of the model during simulations would enable identification of possible clashes which needs to be resolved for achieving more accurate simulation results. Once these clash related conflicts are resolved the simulation run with the model would provide more realistic results in terms of time-cost-quality optimisation. 4D Modelling appears as a key approach to tackle this problem and this is very much supported by the emergence of Building Information Modelling. The statement Q7 advocates that BIM does not contribute much to the time-cost-quality improvement in the projects. More than $85 \%$ of the participants disagree with this idea and recognizes the key role of the BIM in time-cost-quality optimization (Fig.8). The BIM training and learning about BIM technology and software utilized in the BIM-based processes can be lengthy. This lengthy process sometimes discourages individuals to use and benefit from BIM technology. This situation might result in lowering the intellectual capital of the architecture and engineering firms as they would become more disintegrated with new technology in time. This discouraged behaviour and being reluctant to learn to work with BIM can be named as BIM avoidance and harms the organisation's competency. The statement Q8 advocates BIM avoidance by mentioning that "Using BIM makes me lose time in my daily work practice". The majority of the participants, more than $\% 75$ disagreed with this idea and believe that would not cause loss of time in work practices. (Fig.8). The learning curve for some applications used in the Building Information Modelling ecosystem can be steep. This would discourage learners and cause them to quit learning and trying to stick with the old tools and technologies they are familiar with. This, in turn, would contribute to BIM avoidance rather than BIM uptake and adoption. The statement in Q9 expresses that and indicates learning BIM software is difficult. The participants indicated mixed emotions in response to this statement (Fig.8). The majority remained undecisive, while around $40 \%$ agreed with the statement. The problems due to the steep learning curve of some BIM applications can cause some people to be reluctant to move towards implementing BIM processes for their projects. This might also be caused by insufficient training and insufficient level of understanding of the benefits that BIM would bring to everyday design and project management practices. The final statement of the survey argues the statement that in design nonBIM based processes should be chosen instead of BIM based processes. The participants majorly disagreed with this idea, but an important ratio, 25\%, remained indecisive (Fig.8) This might be due to fear caused by the steep learning curve of some BIM tools.

\subsection{Analysis of Results}

Following the exploratory data analysis, a test score is calculated for each individual (respondent) to further analyze their viewpoint on BIM, using the following formula.

$$
A=\frac{1}{n} * \sum_{i=1}^{n} x_{i}
$$

In the Likert Scale questions implemented in our research, 1 represented the level or complete disagreement, 3 represented indecisiveness, 5 represented complete agreement, while 2 and 4 represented the mild levels of disagreement and agreement respectively. A denotes the average (test score) calculated for each individual by taking an arithmetic mean of all scores. ( $n=$ number of statements $=10$ ), Xi represents the score of each individual statement. Fig.7 presents a histogram of test scores.

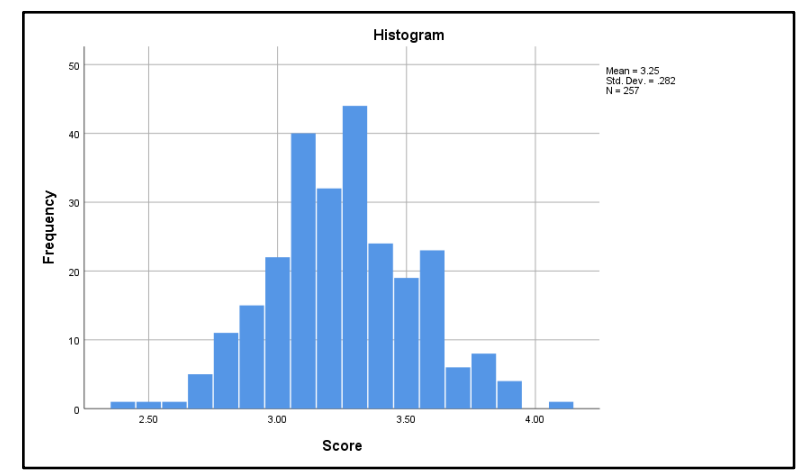

Figure 7. Histogram of Test Scores 

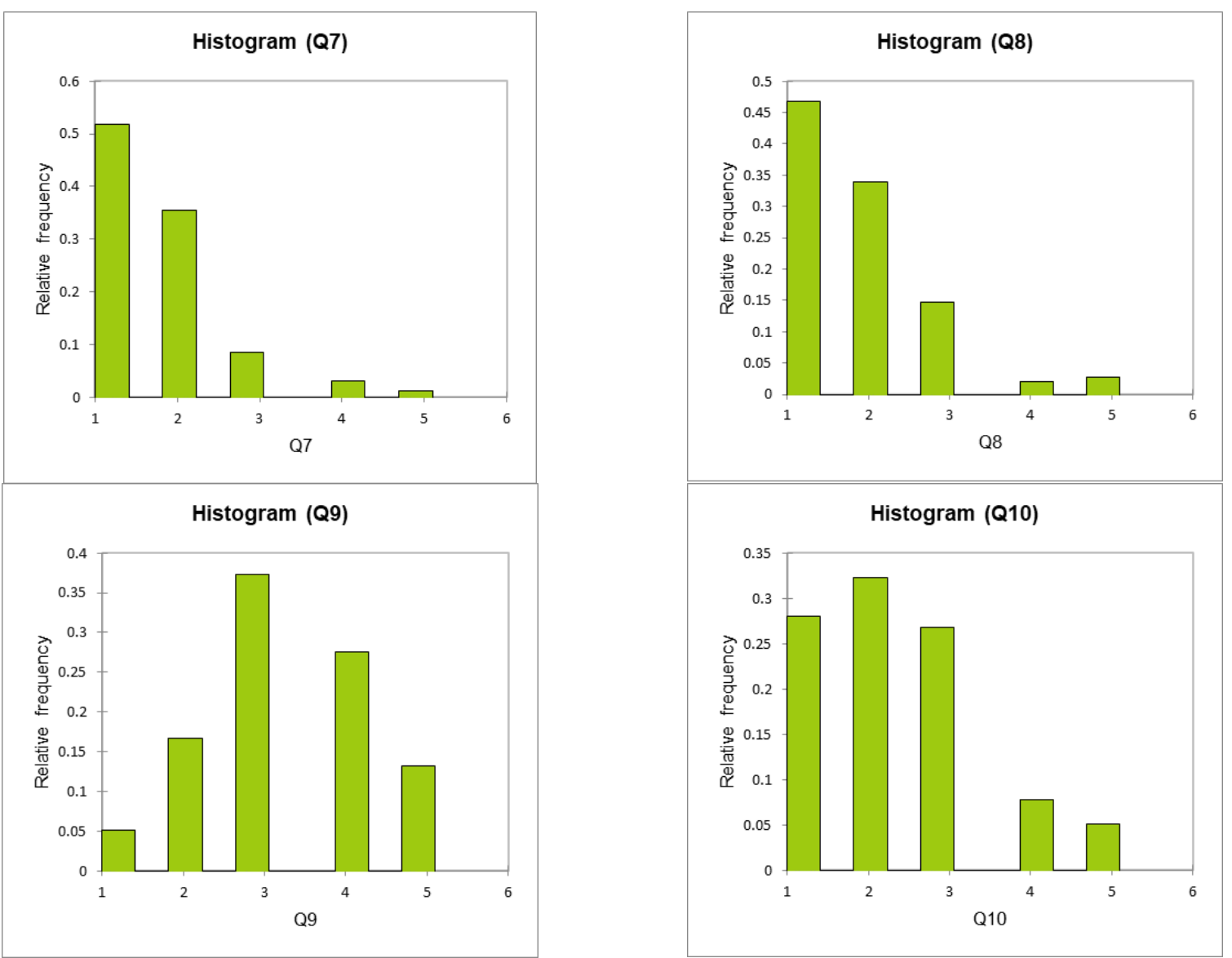

Figure 8. Histograms of Q7-Q10

The questionnaire survey conducted was composed of 10 LikertType questions. The calculated scores were not based on a scale developed previously. The variable type of Likert-type responses is considered as ordinal as the answers indicate a level of agreement. Hypothesis based on ordinal data can be tested with non-parametric statistical tests. In this context, Turan et. al., (2015) clarifies that non-parametric statistical tests need to be used for scores obtained from Likert-type questions when there is no measurement scale used in the study. It should be noted that unless a well-defined/validated measurement scale and scale scores for each scale dimension is present, test scores composed by summation or arithmetic mean of responses to the Likert-Type questions should always be treated as non-metric and be tested with statistical methods relying on the assumptions of ordinal data. As this was the case in our analysis, we have used nonparametric tests to test the following three hypotheses:

- Among the design school students...

- H1.The viewpoint on BIM does not differentiate by gender

- $\quad$ H2.The viewpoint on BIM does not differentiate with the department they are in.

- H3.The viewpoint on BIM does not differentiate with the level/grade of the students.

To test the first hypothesis Mann-Whitney-U test is conducted for the test scores with using gender as the grouping variable. Table 1 shows the results of the Mann-Whitney-U Test.

\begin{tabular}{|lr|}
\hline \multicolumn{2}{|c|}{ Independent-Samples Mann-Whitney U Test } \\
Summary \\
Total N & 257 \\
Mann-Whitney U & 7167.500 \\
Wilcoxon W & 22567.500 \\
Test Statistic & 7167.500 \\
Standard Error & 551.661 \\
Standardized Test Statistic & -.014 \\
Asymptotic Sig.(2-sided & .989 \\
test) & \\
\hline
\end{tabular}

Table 1 Results of the Mann-Whitney-U Test

The results indicated that distributions in the two groups do not differ from each other significantly (Mann-Whiney U: 7167.5, $\mathrm{p}=0.989>0.05$ ). Thus hypothesis, $\mathrm{H} 1$ cannot be rejected within a 95\% confidence level. To test the second hypothesis KruskalWallis test is conducted for the test scores with using department name as the grouping variable. As there were more than 2 departments the Kruskal-Wallis Test was the appropriate method for this case. Table 2 shows the results of the Kruskal-Wallis Test. 


\begin{tabular}{|lr|}
\hline \multicolumn{2}{|c|}{ Test Statistics $^{\mathrm{a}, \mathrm{b}}$} \\
Kruskal-Wallis H & Score \\
df & .255 \\
Asymp. Sig. & 3 \\
a. Kruskal Wallis Test & .968 \\
b. Grouping Variable: dept & \\
\hline
\end{tabular}

Table 2 Results of the Kruskal-Wallis Test

The results indicated that distributions of the test score in the multiple (4) groups of the department do not differ from each other significantly (Kruskal Wallis H: 0.255 , p>0.05). Thus hypothesis, $\mathrm{H} 2$ cannot be rejected within a $95 \%$ confidence level. To test the third hypothesis of the research Kruskal-Wallis test is conducted for the test scores with using level/grade name as the grouping variable. As there were more than 2 levels the KruskalWallis Test was the appropriate method for this case. Table 3 shows the results of the Kruskal-Wallis Test.

\begin{tabular}{|lr|}
\hline \multicolumn{2}{|c|}{ Test Statistics $^{\text {a,b }}$} \\
Kruskal-Wallis H & Score \\
df & 4.795 \\
Asymp. Sig. & 2 \\
a. Kruskal Wallis Test & .091 \\
b. Grouping Variable: level & \\
\hline
\end{tabular}

Table 3. Results of Kruskal-Wallis Test

The results indicated that distributions of the test score in the multiple (3) groups of the department do not differ from each other significantly (Kruskal Wallis H: 4.795, p>0.05). Thus hypothesis, $\mathrm{H} 3$ cannot be rejected within a $95 \%$ confidence level. In summary, all three hypotheses proposed in the study were retained.

\section{DISCUSSION \& CONCLUSIONS}

The study aimed to explore the viewpoint of design school students on Building Information Modelling. The study commenced with a literature review on the foundational concepts regarding BIM. The studies on exploring the viewpoint and attitudes regarding BIM were also investigated as a part of the literature review. The second stage of the study included data collection. The data collection instrument was determined as a questionnaire survey. The response rate was $75 \%$, where the number of respondents was 258 . The responses are analysed using descriptive statistics in the first stage. Inferential statistics is used to test the three hypotheses proposed during the research. The key findings of the research are as follows:

1. The value of BIM in facilitating coordination is well recognized.

2. BIM is considered as an important asset for AEC projects.
3. The role of BIM-based process simulations in enabling the discovery of errors in the early stages of the project is recognized.

4. The participants believe that the use of BIM in the design and construction stages will reduce the error rate in projects.

5. It is recognized that implementing BIM in the design phase would improve the quality and efficiency in the project

6. BIM (as a model or process) is not found as unnecessary for successful knowledge management.

7. BIM is recognized as a contributor to the time-costquality improvement in the projects.

8. It is believed that using BIM does not cause a loss of time in daily work practices

9. There is no agreement on if learning BIM software is difficult or not.

10. The participants believe that BIM-based process should be chosen in the design of buildings

The findings indicate the signs of positive attitude towards the BIM and its utilization in design and construction processes. Further analyses considering the effects of the group difference for the BIM viewpoint have been done based on three hypotheses. The key findings of this phase were:

- $\quad$ Among the design school students...

- The viewpoint on BIM does not differentiate by gender.

- The viewpoint on BIM does not differentiate with the department they are in.

- The viewpoint on BIM does not differentiate with the level/grade of the students.

The limitation of the research was neither developing nor utilizing/adopting an already developed measurement scale. This limitation was due to the timeframe of the research which was considerably short. The future research will focus on conducting an exploratory factor analysis and confirmatory factor analysis to measure the construct more precisely. In this case number of questions needs to be increased and new information should be gathered with another round of data collection.

\section{REFERENCES}

Ahn, E., Kim, M., 2016. BIM awareness and acceptance by architecture students in Asia. Journal of Asian Architecture and Building Engineering, 15(3), 419-424. doi.org/10.3130/jaabe.15.419.

Deniz, G. O., 2018. Emerging cad and bim trends in the aec education: An analysis from students' perspective.

Ghaffarianhoseini, A., Tookey, J., Ghaffarianhoseini, A., Naismith, N., Azhar, S., Efimova, O., \& Raahemifar, K., 2017. Building Information Modelling (BIM) uptake: Clear benefits, understanding its implementation, risks and challenges. Renewable and Sustainable Energy Reviews, 75, 1046-1053. doi.org/10.1016/j.rser.2016.11.083.

HealthKnowledge, 2020.

https://www.healthknowledge.org.uk/public-healthtextbook/research-methods/1a-epidemiology/methods-ofsampling-population (1 June 2020) 
ISO, B., 2018, 19650-1: 2018. BSI Standards Publication Organization and digitization of information about buildings and civil engineering works, including building information modelling (BIM)-Information management using building information modelling.

Lee, G., Sacks, R., Eastman, C. M., 2006. Specifying parametric building object behavior (BOB) for a building information modeling system. Automation in construction, 15(6), 758-776. doi.org/ 10.1016/j.autcon.2005.09.009.

Research Advisors, 2020. https://www.researchadvisors.com/tools/SampleSize.htm (1 June 2020)

Sacks, R., Eastman, C., Lee, G., \& Teicholz, P., 2018. BIM handbook: a guide to building information modeling for owners, designers, engineers, contractors, and facility managers. John Wiley \& Sons.

Shelbourn, M., Macdonald, J., McCuen, T., Lee, S., 2017. Students' perceptions of BIM education in the higher education sector: A UK and US perspective. Industry and Higher Education, 31(5), 293-304. doi.org/10.1177/0950422217725962.

Sotelino, E. D., Natividade, V., Travassos do Carmo, C. S., 2020. Teaching BIM and Its Impact on Young Professionals. Journal of
Civil Engineering Education, 146(4), 05020005. doi.org/10.1061/(ASCE)EI.2643-9115.0000019.

Suwal, S., Singh, V., 2018. Assessing students' sentiments towards the use of a Building Information Modelling (BIM) learning platform in a construction project management course. European Journal of Engineering Education, 43(4), 492-506. doi.org/10.1080/03043797.2017.1287667.

Turan, İ., Şimşek, Ü., \& Aslan, H., 2015. Eğitim araştırmalarında likert ölçeği ve likert-tipi soruların kullanımı ve analizi. Sakarya Üniversitesi Eğitim Fakültesi Dergisi, 30(1), 186-203.

Wong, J., \& Yang, J., 2010. Research and application of building information modelling (BIM) in the architecture, engineering and construction (AEC) industry: a review and direction for future research. In Proceedings of the 6th international conference on innovation in architecture, engineering \& construction (AEC) (Vol. 1, pp. 356-365). Loughborough University, UK.

Zou, P. X., Xu, X., Jin, R., Painting, N., Li, B., 2019. AEC students' perceptions of BIM practice at Swinburne University of Technology. Journal of professional issues in engineering education and practice, 145(3), 05019002. doi.org/10.1061/(ASCE)EI.1943-5541.0000410. 